\title{
Student estimations of peer alcohol consumption: Links between the Social Norms Approach-and the Health Promoting University concept
}

\author{
Christiane Stock ${ }^{c}$, John McAlaney ${ }^{a}$, Claudia Pischke ${ }^{b}$, Bart Vriesacker ${ }^{\text {d,e, }}$, Guido Van Hal ${ }^{d}$, Yildiz \\ Akvardar $^{\mathrm{f}}$, Olga Orosova ${ }^{\mathrm{h}}$, Ondrej Kalina ${ }^{\mathrm{h}}$, Francisco Guillen-Grima', Bridgette M Bewick ${ }^{\mathrm{j}}$ \\ ${ }^{a}$ Division of Psychology, University of Bradford, Bradford, BD7 1DP, United Kingdom \\ ${ }^{\mathrm{b}}$ Leibniz-Institute for Prevention Research and Epidemiology BIPS, 28359 Bremen, Germany \\ ${ }^{c}$ Unit for Health Promotion Research, University of Southern Denmark, 6700 Esbjerg, Denmark \\ ${ }^{d}$ Medical Sociology and Health Policy, University of Antwerp, 2610 Antwerp, Belgium \\ ${ }^{\mathrm{e}}$ Research \& Development, Occupational Health Services Mensura, 2000 Antwerp, Belgium \\ ${ }^{f}$ Department of Psychiatry, Marmara University Medical School 34722 Istanbul, Turkey \\ ${ }^{\mathrm{h}}$ Department of Educational Psychology \& Psychology of Health, PJ Safarik University in Kosice, \\ 04011 Košice, the Slovak Republic
}

' Department of Health Sciences, Public University of Navarra, 31008 Pamplona, Navarra, Spain and Preventive Medicine Division, University of Navarra Clinic, 31008 Pamplona, Spain

${ }^{j}$ School of Medicine, Leeds Institute of Health Sciences, Academic Unit of Psychiatry and Behavioural Sciences, University of Leeds, Leeds, LS2 9LJ, United Kingdom

\begin{abstract}
(max 250 words)
Background: The Social Norms Approach, with its focus on positive behaviour and its consensus orientation, is a health promotion intervention of relevance to the context of a Health Promoting University. In particular the approach could assist with addressing excessive alcohol consumption. This article aims to I) discuss the link between the Social Norms Approach and the Health Promoting University and II) analyse estimations of peer alcohol consumption among European university students.
\end{abstract}

Methods: A total of 4,392 students from universities in 6 European countries and Turkey were asked to report their own typical alcohol consumption per day and to estimate the same for their peers of same sex. Students were classified as accurate or inaccurate estimators of peer alcohol 
consumption. Sex, age, country, born outside the country, study subject, being a "typical student" were examined as predictors for an overestimation.

Results: A percentage of $72 \%$ of male and $51 \%$ of female students were identified as having accurate estimations about the amount of alcoholic drinks consumed per day by their peers, while the percentage of students overestimating the norm ranged from 18\% among males from Turkey to $89 \%$ among females from the United Kingdom. Male students, older students, those studying year 3 and above, and Turkish and Danish students were more likely to accurately estimate their peers' alcohol consumption. Independent from these factors students accurate estimation of peers' drinking decreased significantly with increasing personal consumption.

Conclusion: Since correct estimates of peer alcohol consumption appear to affect personal drinking behaviour positively, social norms interventions targeted at correcting possible misperceptions about peer alcohol use among students may be a useful health promotion tool in the context of a Health Promoting University.

Key words: Social Norms Approach, alcohol consumption, university students, Health Promoting University

\section{Introduction}

This article aims to explore to what extent the Social Norms Approach is a useful intervention strategy in the context of a Health Promoting University. Furthermore, we use empirical data of alcohol consumption among European students and compare it with estimated consumption of their peers in order to elucidate a need for correcting misperceived norms in university students.

\section{The Health Promoting University concept}

The concept of the Health Promoting University has been developed as an example of settingsbased health promotion in the late 1990s and has been supported and legitimated by the World Health Organization (WHO) through developing and publishing a strategic framework for the Health Promoting Universities project (Tsouros et al., 1998; Cawood et al., 2010). Three main arguments have been raised for promoting health within institutions of higher education: (1) universities are large institutions in which many people live and experience different aspects of their lives; (2) students will become professionals and leaders in society and that therefore universities can increase the commitment to health in a wide range of disciplines; and (3) universities can set an example of good practice with outreach into the community (Tsouros et al., 1998). In addition, universities are important regarding health promotion as entry to them often coincides with transition into adulthood and living away from the parental home for the first time. The WHO framework identified eight key objectives for a Health Promoting University: promoting health and sustainable policies and planning throughout the university; providing healthy working 
environments; offering healthy and supportive social environments; establishing and improving primary health care; facilitating personal and social development; ensuring a healthy and sustainable physical environment; encouraging wider academic interests and developments in health promotion; and developing links with the community. The process towards a Health Promoting University requires a commitment to health by the senior-level management and institutional and cultural changes aiming at embedding the principles and aims of a Health Promoting University into the organizational structures and practices of the institution. Based on such structural processes innovative action for health promotion, such as implementing healthy policies and health promotion interventions, should take place that focus on the key objectives. Universities then need to decide which type of health promotion interventions should be given priority. The Social Norms Approach is an example of an intervention approach that has potential to facilitate personal and social development among students; this being one of the key objectives of a Health Promoting University.

\section{What is the Social Norms Approach?}

Social norms are the "perceptions and beliefs what is 'normal' behaviour in the people close to us" (Berkowitz, 2005, p.3) and appear to be a key factor modifying drug use behaviour among young adults (Perkins et al., 1999; Perkins and Craig, 2003). Previous research suggests that young adults tend to overestimate drug use including alcohol in their respective peer group (e.g. Boot et al., 2012) and that these incorrect perceptions are predictive of higher rates of personal use (Perkins and Craig, 2003; Johannessen and Glider, 2003; Haines and Barker, 2003; Kilmer at al., 2006; Bewick et al., 2008a 2008b).

Overestimations of peer alcohol use and associations with higher rates of personal use have been widely demonstrated among US college students in the past two decades (Perkins and Berkowitz, 1986; Perkins et al., 1999; Perkins et al., 2005). Berkowitz (2004) stated in a review that peer influences have a greater impact on individual behaviour than biological, personality, familial, religious, cultural and other influences. In recent years, an increasing number of studies indicate a similar pattern of overestimation of peer alcohol use and associated increased personal use among European university and college students (McAlaney et al., 2012, Boot et al., 2012; Franca et al., 2010; McAlaney and McMahon, 2007). For example, in a study with French students, Franca et al. (2010) found that $56 \%$ of the students overestimated the prevalence of heavy episodic drinking behaviour in their peers. Overestimations were associated with higher rates of personal heavy episodic drinking and correlates for an increased alcohol use included cannabis and tobacco use, academic discipline, sex, and the number of friends. Similarly, Arbour-Nicitopoulos et al. (2010) reported correlates with alcohol use. Being in a relationship, living away from home, being white, and the perception that a typical student often consumed alcohol $\mathrm{n}$ the past 30 days all 
predicted personal alcohol use. Predictors for the observed overestimations (vs. correct estimates) of peer alcohol consumption are however not generally well understood.

Social norms interventions work on the premise that if overestimations are challenged then the social pressure on the individual will lessen and their own rate of use will fall. In the case of alcohol consumption, a social norms campaign may consist of surveying a student population to identify the actual and perceived rates of alcohol use, and then presenting this information back to the student population. Traditional social norms provided social norms feedback to student populations through mass media campaigns and a variety of peer education activities. This approach has been found to be an effective method of reducing alcohol and drug harm at several college campuses (e.g. Perkins and Craig, 2003), and has also been used successfully to address alcohol related harms (Turner et al., 2008). However the social norms approach is a harm reduction approach and considers abstinence, though optimal from a health perspective, as an unrealistic goal for the lifestyle of adolescents. Therefore the social norms approach faces the ethical dilemma that for most students it is likely to reduce the consumption, but for some students with very low or no consumption it might encourage use.

\section{The potential of the Social Norms Approach for a Health Promoting University}

The Social Norms Approach is most effective when delivered as part of ongoing and multifaceted programmes that challenges misperceived norms within the population. As such there is a need for Social Norms practitioners to be mindful of the ability for the context in which the messages are embedded to undermine the message content. In particular practitioners should be aware of the synergistic relationship between the wider context and the individual campaigns. Therefore although a Social Norms Approach is sometimes implemented without incorporating a systems perspective it is posited that the approach will be more effective if developed in tandem with organizational practice. Specifically the Social Norms Approach has key characteristics that make it suitable for application in the context of a Health Promoting University. Firstly, the settings approach in general draws upon the work of theorists that are not so much concerned with the avoidance of ill-health as with the creation of positive health, described as salutogenic approach by Antonovsky (1996). In line with the salutogenic paradigm the Social Norms Approach focuses on the positive behaviour rather than blaming deviant or risk behaviours. Secondly, one of the principles and values of a Health Promoting University is a consensus orientation (Dooris, 2000, 2002). The Social Norms Approach offers the chance to address a potentially conflict-prone theme such as alcohol and other drug use in a way that does not conflict with consensus building communication practices in the setting. The Social Norms Approach does not condemn drug use and does not put moral pressure on students who decide to use alcohol and other drugs, but rather informs students about the predominant lifestyle choices in their own community. Since the data used are derived from their own community the Social Norms Approach helps to facilitate 
ownership. This is important when addressing alcohol and other drugs as there is a long history of prevention programmes with limited success among young people (Foxcroft et al., 2003). The ineffectual nature of some prevention programmes may be partially attributed to their following paternalistic perspectives that conflict with the wish for autonomy in decision making among students. Thirdly, the Social Norms Approach has been successfully applied to addressing and influencing norms across a number of topics ranging from alcohol consumption to sexual harassment (Berkowitz, 2003). In a healthy setting, different actors, themes and outcomes are interlinked with each other (Dooris, 2006), so this holistic approach could be applied to themes subsequently included in the settings agenda.

In order to investigate the need for a Social Norms intervention among university students in Europe, this article uses data from the baseline data collection of the Social Norms Intervention for the Prevention of Polydrug UsE (SNIPE) study to explore (1) to what extent European university students have an accurate (vs. inaccurate) estimation of their peers' amount of alcoholic drinks consumed per day; (2) to identify predictors of accurate estimation of peer alcohol use; and (3) whether an accurate estimation is associated with a reduced likelihood of personal excessive drinking among university and college students in six European countries and Turkey.

\section{Methods}

\section{Study design}

The study design is reported in detail elsewhere (Pischke et al., 2012). The current article is based on the baseline data collected in the SNIPE study, a European collaborative project aimed at assessing the potential of the Social Norms Approach to reduce alcohol and other drug use among university and college students from six European countries and Turkey. Ethical approval for the SNIPE study was obtained at all study sites and permission to recruit students was obtained from university leaderships.

\section{Data collection}

Data collection is outlined in detail in the study protocol (Pischke et al., 2012). In 2012 an online survey was promoted at all study sites (typically 2 to 5 institutions per country) using a range of techniques including email, social media, classroom announcements, announcements on virtual learning environments, printed flyers and stalls in social areas. Anonymous online surveys can be a reliable form of data collection when conducted among computer literate populations such as university students (Kypri et al., 2004). The survey contained items on age and sex, year of study, main area of study (Arts, Business and Law, Engineering, Health and Medicine, Sports Science, Media, Sciences, Social and Educational Sciences) and whether the student was born in another 
country. Students were also asked: "How typical a student of your university do you consider yourself to be?" with four response categories from "very untypical" to very typical". Participants were provided with a definition of an alcoholic drink as half a pint of lager or beer, a shot of vodka, a small glass of wine, a shot of raki, or a small bottle of a ready to drink beverage and were then asked for the number of drinks: "How many alcoholic drinks would you normally have on a day that you do drink alcohol?". Students who drank alcohol entered the number of drinks while students who did not drink alcohol entered 0 . Similarly students were asked to estimate: "How many alcoholic drinks do you think most (at least 51\%) of the students of your sex at your university normally have on days that they do drink alcohol?"

The final sample included 4,392 participants. Participation by students from universities in the United Kingdom and Spain were lower compared to the other countries (table 1). The relatively low participation rate was attributed to barriers faced around participant recruitment; for example changes in university regulations meant it was not possible to email notifications directly to all registered students.

\section{Statistical analysis}

Data on reported personal behaviour were summarized using means and standard deviation (SD). Using IBM SPSS 20 we applied Wilcoxon signed ranks test to test for differences between personal drinking and perceived peer drinking. Binary logistic regression was used to determine odds ratios $(\mathrm{OR})$ and $95 \%$ confidence intervals $(95 \% \mathrm{Cl})$ for factors associated with accurate estimation of peer drinking. Students were classified as accurate estimators if they estimated the number of drinks per day among peers of their sex up to the $75 \%$ percentile of the actual number of drinks consumed per day in this group. The $75 \%$ percentile was used as cut-off, as it represents data from the majority of students. Personal number of alcoholic drinks per day was entered as independent variable into the regression model. Sex, age, country, born outside the country, typicality as student from low to high were included for adjustment in the regression models. In addition medicine/health as study subject was added to the model as independent variable as we assumed that students studying medicine and other health-related subject are more likely to estimate the alcohol consumption among peers accurately. We assumed this higher level of accuracy due to students of medicine and health-related subjects being more likely to have access to information and data on health behaviour.

\section{Results}

The mean of the typical number of drinks per day was 3.5 (3.6 SD) drinks in the whole sample and differed between the seven countries ranging from 2.1 (3.6 SD) among Turkish students to 5.9 (4.5 
SD) among Danish students. For males the mean number of drinks was 4.5 (4.9 SD) drinks, while the estimated number of drinks among male peers was being significantly higher at 6.2 (4.9 SD) drinks per day (see Table 1). For females the mean number of drinks was 3.1 (2.8 SD) while the estimated number among females peers was higher with 5.5 (3.7 SD) drinks per day. In all countries students provided significantly higher estimates of the number of drinks per day consumed by their peers when compared with the actual number of drinks reportedly consumed (Wilcoxon test $p<0.001$ ).

The proportion of students classified as accurate estimators were those who estimated the number of drinks per day among peers of their sex up to the $75 \%$ percentile (cut-off) of the actual number of drinks consumed per day in this group. Overall this proportion was $72 \%$ among males (ranging from 52\% in Belgium to $82 \%$ in Germany and Turkey) and 51\% among females (ranging from $34 \%$ in the Slovak Republic to $87 \%$ in Turkey).

Insert table 1 here

Female students had lower odds for accurate estimations as did students in the 1st or 2nd year of studies (see Table 2). Consequently older students were more likely to be accurate estimators. When compared to Turkish students as reference Belgium, German, Slovakian and Spanish students were less likely to estimate their peers' drinking accurately, while Danish students did not differ significantly from Turkish students. Whether students perceive themselves as typical student, whether they study medicine/health and whether they are born in another country were not associated with accurate estimation. However, accurate estimation of peers' drinking decreased significantly with increasing numbers of own drinks per day.

Insert table 2 here

\section{Discussion}

Overall $28 \%$ of male and $49 \%$ of females overestimated the number of drinks per day among their fellow students of same sex. This suggests that social norms feedback would be useful in correcting the inaccurate perceptions of normative alcohol consumption in a substantial number of students.

Bertholet et al. (2011) examined predictors for accurate and inaccurate estimations of alcohol use among 9686 Swiss students. They found that approximately 19\% made a correct estimate compared to $46 \%$ of the students overestimating drinking behavior among their peers. Those students who overestimated rates of alcohol consumption in their peers also drank more. Except for current drinking, variables such as age, education level, occupation, living environment, family history of alcohol problems did not predict overestimations of peer alcohol use. A second study compared correct and overestimates (and underestimates) by drinking norm on the campus (i.e., median frequency of alcohol use at the campus: once per month, twice per month, once per 
week; Perkins, 2007). Overestimates were apparent for $87 \%, 86 \%$, and $56 \%$ of the students in each category. Correct estimates were prevalent among $9 \%, 10 \%$, and $41 \%$ of the students. In addition, Perkins compared light drinkers or abstainers who overestimated the norm to those accurately perceiving the campus norm and found that those who overestimated the norm felt less valued as a person at their school, were unhappier at the school most of the time, felt that they fit in less and that it was not important to work with other students to improve the school compared to those who accurately perceived the norm. To our knowledge these two studies are the only ones to date investigating predictors of overestimations of alcohol consumption. Further, we are not aware of previous studies comparing predictive factors for perceptions about peer alcohol use in several EU countries.

The proportion of students accurately estimating the alcohol consumption of peers differed between countries with higher levels found in Denmark and Turkey and relatively lower levels in Belgium, Spain, Slovak Republic and Germany. In the UK the level of accurate estimation was high only among males, but low among females. Consumption patterns cannot explain these differences, as students from Denmark reported relatively high levels of alcohol consumption and students from Turkey reported relatively low levels, while in both countries the proportion of accurate estimators was high. Moreover, most differences between countries remained significant even after adjusting for own alcohol consumption and other factors like sex and age. These country differences are therefore hard to explain from the current data.

Female students were less likely to estimate the consumption of female peers accurately. A metaanalysis has also found that females are misperceiving more (Borsari and Carey, 2003) and this has been attributed to the fact that females may be more influenced by the social environment or that women may be less involved in the culture of alcohol use and therefore misperceive it more (Berkowitz, 2004). Older students who were in year three or above of their studies were more likely to be accurate estimators of peer drinking, which is most likely due to the fact that they have more time to observe their peers' behaviour. McAlaney and McMahon (2007) also found less misperceptions among older students. Bertholet et al. (2011), however, did not find an association between age and estimates of peer alcohol use.

Although we assumed that students studying medicine or any other health-related subject are more likely to estimate the alcohol consumption among peers accurately this assumption was not supported by our analysis. Moreover, being born outside the country and seeing oneself as a typical student were also not associated with accurate estimation of peer drinking. There are unknown factors which were not included in this study that are related to overestimating alcohol use in the peer group that, had the data been available, helped to explain the moderators and mediators of estimation. Bertholet et al. (2011) examined education level, occupation, living environment, family history of alcohol problems and could not demonstrate a relationship between these factors and accurate and inaccurate estimations of alcohol use. Perkins (2007) found a sense of alienation from campus life in a sub-analysis with light drinkers and abstainers 
who overestimated drinking rates among their peers. Other factors not explored in our study such as the current portrayal of alcohol use in the media or alcohol consumption among friends outside of university may be more salient when estimating peer alcohol use.

Accurate estimation of peer alcohol consumption was strongly associated with low number of alcoholic drinks consumed per day. This indicates that independent of the country, sex and other factors, students who have accurate estimation of their peers drinking are more likely to drink moderate amounts of alcohol per day when compared to overestimating students. This finding lends support to the use of social norms feedback to create realistic perceptions of the level of alcohol consumption of peers. Since such feedback has been successful in reducing excessive alcohol drinking among students in some studies (Neighbors et al., 2004; Perkins and Craig, 2003) we assume that the approach might lead to lower consumption in European students as well.

Limitations of the current study need to be acknowledged. We used self-reported data of alcohol consumption and potential under-reporting by the respondents needs to be taken into account, although previous research has demonstrated that self-reported data of alcohol use can be reliable (Del Boca and Darkes, 2003; Lintonen et al., 2004). Due to the self-selecting nature of the sample we cannot rule out that those who responded have different alcohol consumption behaviours than the whole student body at each institution. This may be particularly true for male students, because they were less likely than females to participate in the study. In addition prevalence data on actual alcohol consumption needs to be interpreted with caution, because in some countries (e.g. the UK) the sample size was low. As the data are cross-sectional the direction of effects cannot be ascertained and the findings could only talk of associations not causations. The analysis assumes that perceptions are the cause of behaviour rather than behaviour being the cause of perceptions. This assumption is supported by longitudinal studies in the field, although it has been noted that a degree of reciprocal causality is present (Neighbors et al., 2006).

The SNIPE study was designed as a standalone feasibility study (Pischke et al., 2012) without being embedded in a whole system approach of a Health Promoting University. Therefore any testing of the effectiveness of the social norms intervention would only provide evidence for effectiveness of an intervention in a setting, but would not contribute to the sparse evidence-base of comprehensive settings approaches, which is a methodologically difficult and complex task (Dooris, 2006). We argue that universities who are developing a comprehensive whole university approach towards better health of students may take advantage of such feasibility research in order to decide on the usefulness of the Social Norms Approach for addressing their specific health goals. Dooris (2006) proposes a model that highlights the need to combine organization development with high visibility projects in settings projects. A Social Norms Approach intervention could be such a high visibility project that meets the need to correct misperceived norms among students. The positive messages encouraging students to engage in only moderate or no alcohol consumption, as the majority of students do, are in accordance with the focus on 
resources and competencies that the salutogenetic paradigm of the Health Promoting University suggests. Moreover, one can assume that organizational practices of a Health Promoting University such as non-alcoholic social events and a limitation of alcohol availability on campus provide an environment that makes social norms interventions even more effective. In conclusion, we argue that the Social Norms Approach and the Health Promoting University would mutually support each others' aims when combined in health promotion practice.

\section{References}

Antonovsky A. The salutogenic model as a theory to guide health promotion. Health Prom Int 1996; 11(1):11-18

Arbour-Nicitopoulos KP, Kwan MY, Lowe D, Taman S, Faulkner GE. Social norms of alcohol, smoking, and marijuana use within a Canadian university setting. J Am Coll Health 2011,59(3):1916.

Berkowitz AD. The social norms approach: theory, research, and annotated bibliography. Trumansburg, NY: Berkowitz, 2004.

Berkowitz AD. An overview of the Social Norms Approach. In: Changing the culture of college drinking: A socially situated health communication campaign. Cresskill, NJ: Hampton Press, 2005

Berkowitz AD. Application of Social Norms Theory to other health and social justice issues. In: Perkins HW (ed.) The social norms approach to preventing school and college age substance abuse: A handbook for educators, counselors, and clinicians. San Francisco, CA, Jossey-Bass, 2003

Bertholet N, Gaume J, Faouzi M, Daeppen JB, Gmel G. Perception of the amount of drinking by others in a sample of 20-year-old men: the more I think you drink, the more I drink. Alcohol Alcohol 2011; 46(1):83-7.

Bewick BM, Trusler K, Barkham M, Hill AJ, Cahill J, Mulhern B, 2008. The effectiveness of webbased interventions designed to decrease alcohol consumption - A systematic review. Prev Med 2008a; 47:17-26.

Bewick BM, Trusler K, Mulhern B, Barkman M, Hill AJ: The feasibility and effectiveness of a webbased personalised feedback and social norms alcohol intervention in UK university students: $A$ randomised controlled trial. Addict Behav 2008b; 33:1192-1198.

Boot CR, Dahlin M, Lintonen T, Stock C, van Hal G, Rasmussen S, McAlaney J. A survey study on the associations between misperceptions on substance use by peers and health and academic outcomes in university students in North-West Europe. Int J Disabil Hum Dev 2012; 11(3):273-279. 
Borsari B, Carey, KB. Descriptive and Injunctive Norms in College Drinking: A Meta-analytic Integration. J Stud Alcohol 2003; 64:331-334.

Del Boca FK, Darkes J. The validity of self reports of alcohol consumption: state of the science and challenges for research. Addiction 2003; 98:1-12.

Dooris M. Healthy settings: challenges to generating effectiveness. Health Prom Int 2006; 21(1): pp. 55-65.

Cawood J, Dooris M, Powell S. Healthy universities: shaping the future. Perspect Pub Health 2010; 130(6):259-260.

Dooris M. Promoting sustainable health within a university setting: a case study. In: Sonntag U, Gräser S, Stock C, Krämer A. (eds.) Gesundheitsfördernde Hochschulen. Weinheim: Juventa, 2000, pp. 163-169.

Dooris M. The Health Promoting University: opportunities, challenges and future developments. Prom Educ 2002; Suppl.1: 20-24.

Foxcroft DR, Ireland D, Lister-Sharp DJ, Lowe G, Breen R: Longer-term primary prevention for alcohol misuse in young people: a systematic review. Addiction 2003; 98(4):397-411.

Franca LR, Dautzenberg B, Reynaud. Heavy episodic drinking and alcohol consumption in French colleges: The role of perceived social norms. Alcohol Clin Exp Res 2010; 34(1):164-174.

Haines MP, Barker G: The NIU experiment: A case study of the social norms approach. In: Perkins HW (ed) The social norms approach to preventing school and college age substance abuse: A handbook for educators, counselors, and clinicians. San Francisco, CA: Jossey-Bass, 2003, pp.2134.

Johannessen K, Glider P. The University of Arizona's campus health social norms media campaign. In: Perkins HW (ed) The social norms approach to preventing school and college age substance abuse: A handbook for educators, counselors, and clinicians. San Francisco, CA: Jossey-Bass, 2003, pp.65-82.

Kilmer JR, Walker DD, Lee CM, Palmer RS, Mallett KA, Fabiano P, Larimer ME: Misperceptions of college student marijuana use: implications for prevention. J Stud Alcohol 2006; 67(2):277-281..

Kypri K, Gallagher SJ, Cashell-Smith ML. An internet-based survey method for college student drinking research. Drug Alcohol Depend ;76(1):45-53.

Lintonen, T., Ahlstrom, S., Metso, L.. The reliability of drinking self-reports in adolescence. Alcohol Alcohol 2004; 39, $362-368$ 
McAlaney J, McMahon J: Normative beliefs misperceptions and heavy episodic drinking in a British student sample. J Studies Alcohol Drugs 2007; 68:385-392.

McAlaney J, Boot C, Dahlin M, Lintonen T, Stock C, Rasmussen S, Van Hal G. A comparison of substance use and normative beliefs in North West European university and college students. Int J Disability Hum Development 2012; 11(3):281-287.

Neighbors C, Larimer ME, Lewis MA. Targeting misperceptions of descriptive drinking norms: Efficacy of a computer delivered personalised normative feedback intervention. J Consult Clin Psychol 2004; 72(3):434-447.

Neighbors, C., Dillard, A.J., Lewis, M.A., Bergstrom, R.L., Neil, T.A. Normative misperceptions and temporal precedence of perceived norms and drinking. J Stud Alcohol 2006; 67, $290-299$

Perkins HW, Berkowitz AD. Perceiving the community norms of alcohol use among students: some research implications for campus alcohol education programming. Int J Addict 1986, 21(9-10):96176.

Perkins HW, Craig DW. The Hobart and William Smith College experiment: A synergistic social norms approach using print, electronic media, and curriculum infusion to reduce collegiate problem drinking. In: Perkins HW (ed) The social norms approach to preventing school and college age substance abuse: A handbook for educators, counselors, and clinicians. San Francisco, CA: Jossey-Bass, 2003, pp.:35-46.

Perkins HW, Haines MP, Rice R. Misperceiving the college drinking norm and related problems: a nationwide study of exposure to prevention information, perceived norms and student alcohol misuse. J Stud Alcohol 2005; 66(4):470-478.

Perkins HW, Meilman PW, Leichliter JS, Cashin JR, Presley CA: Misperceptions of the norms for the frequency of alcohol and other drug use on college campuses. J Am Coll Health 1999; 47(6):253258.

Perkins HW. Misperceptions of peer drinking norms in Canada: another look at the "reign of error" and its consequences among college students. Addict Behav 2007; 32(11):2645-56.

Pischke CR, Zeeb H, van Hal G, Vriesacker B, McAlaney J, Bewick BM, Akvardar Y, Guillen-Grima F, Orosova O, Salonna F, Kalina O, Stock C, Helmer SM, Mikolajczyk RT . A feasibility trial to examine the social norms approach for the prevention and reduction of licit and illicit drug use in European university and college students. BMC Pub Health, 2012: 12, p. 882

Tsouros AD, Dowding G, Dooris M. Strategic framework for the Health Promoting Universities project. In: Tsouros AD, Dowding G, Thompson J, Dooris M (eds.) Health Promoting Universities. Copenhagen: World Health Organization, 1998, pp. 111-126. 
Turner J, Perkins HW, Bauerle J. Declining negative consequences related to alcohol misuse among students exposed to a social norms marketing intervention on a college campus. J Am Coll Health 2008; 57(1):85-93. 
Table 1: Male and female students own consumption and their estimation of the drinking of their peers (typical number of alcoholic drinks per day on a day when drinking alcohol)

\begin{tabular}{|c|c|c|c|c|c|}
\hline \multirow[b]{2}{*}{ Country (n) } & \multicolumn{2}{|c|}{$\begin{array}{l}\text { Typical number of } \\
\text { drinks per day }\end{array}$} & \multicolumn{2}{|c|}{$\begin{array}{l}\text { Perceived number of } \\
\text { drinks among the } \\
\text { majority of peers of } \\
\text { same sex }\end{array}$} & \multirow{2}{*}{$\begin{array}{c}\text { Accurate } \\
\text { estimators of } \\
\text { peer drinking } \\
\%\end{array}$} \\
\hline & MEAN (SD) & $\begin{array}{c}75 \% \\
\text { percentile }^{a}\end{array}$ & MEAN (SE) & $P$ value & \\
\hline \multicolumn{6}{|c|}{ Males } \\
\hline Belgium $(n=85)$ & $4.4(3.7)$ & 6 & $6.9(4.1)$ & $<0.001$ & 52 \\
\hline Denmark $(n=100)$ & $6.8(5.8)$ & 10 & $8.8(4.1)$ & $<0.001$ & 78 \\
\hline Germany (n=206) & $5.4(4.3)$ & 8 & $6.2(3.6)$ & 0.004 & 80 \\
\hline Slovak Republic $(n=389)$ & $5.3(4.8)$ & 8 & $8.0(4.8)$ & $<0.001$ & 61 \\
\hline Spain $(n=50)$ & $5.0(2.4)$ & 6 & $6.1(4.4)$ & $<0.001$ & 76 \\
\hline UK $(n=32)$ & $3.3(4.3)$ & 5 & $5.3(3.6)$ & 0.009 & 82 \\
\hline Turkey $(n=386)$ & $2.6(4.9)$ & 4 & $3.3(4.5)$ & $<0.001$ & 82 \\
\hline All countries $(n=1248)$ & $4.5(4.9)$ & 6 & $6.2(4.9)$ & $<0.001$ & 72 \\
\hline \multicolumn{6}{|c|}{ Females } \\
\hline Belgium ( $n=332)$ & $2.9(2.9)$ & 4 & $4.8(2.7)$ & $<0.001$ & 54 \\
\hline Denmark $(n=354)$ & $5.7(4.1)$ & 8 & $7.6(3.3)$ & $<0.001$ & 69 \\
\hline Germany (n=295) & $3.8(3.2)$ & 5 & $5.3(2.6)$ & $<0.001$ & 66 \\
\hline Slovak Republic $(n=1520)$ & $2.9(2.3)$ & 4 & $6.1(4.0)$ & $<0.001$ & 34 \\
\hline Spain $(n=131)$ & $3.3(2.2)$ & 4 & $5.0(2.8)$ & $<0.001$ & 52 \\
\hline UK $(n=72)$ & $3.4(4.0)$ & 4 & $6.5(5.1)$ & $<0.001$ & 11 \\
\hline Turkey $(n=440)$ & $1.6(1.9)$ & 2 & $2.7(1.7)$ & $<0.001$ & 87 \\
\hline Whole sample $(n=3144)$ & $3.1(2.8)$ & 4 & $5.5(3.7)$ & $<0.001$ & 51 \\
\hline
\end{tabular}

${ }^{\mathrm{a}} 75 \%$ percentile used as cut-off for accurate estimation ${ }^{\mathrm{b}}$ Wilcoxon signed ranks test to test for differences between actual drinking and perceived peer drinking 
Table 2: Factors associated with accurate estimation of the number of drinks per day among peers of own sex

\begin{tabular}{|c|c|c|c|c|}
\hline & \multirow[t]{2}{*}{ P-value } & \multirow{2}{*}{$\begin{array}{c}\text { Odds ratio }{ }^{a} \\
\text { OR }\end{array}$} & \multicolumn{2}{|c|}{ 95\% C.I.for OR } \\
\hline & & & Lower & Upper \\
\hline Sex & & & & \\
\hline Male & & 1.00 & & \\
\hline Female & $<0.001$ & 0.27 & 0.23 & 0.34 \\
\hline Age (per year) & 0.011 & 1.03 & 1.01 & 1.07 \\
\hline Year of study & & & & \\
\hline Higher years of study & & 1.00 & & \\
\hline 1 st or 2 nd year of study & 0.009 & 0.81 & 0.69 & 0.95 \\
\hline Study subject & & & & \\
\hline Other & & 1.00 & & \\
\hline Medicine/health as study subject & 0.756 & 0.97 & 0.79 & 1.18 \\
\hline Country & & & & \\
\hline Turkey & & 1.00 & & \\
\hline Belgium & $<0.001$ & 0.28 & 0.19 & 0.39 \\
\hline Denmark & 0.107 & 1.40 & 0.93 & 2.11 \\
\hline Germany & 0.034 & 0.67 & 0.47 & 0.97 \\
\hline Slovak Republic & $<0.001$ & 0.14 & 0.10 & 0.19 \\
\hline Spain & $<0.001$ & 0.32 & 0.21 & 0.50 \\
\hline United Kingdom & $<0.001$ & 0.04 & 0.02 & 0.09 \\
\hline Typicality as student & & & & \\
\hline Very untypical/untypical & & 1.00 & & \\
\hline Very typical/typical & 0.758 & 1.07 & 0.69 & 1.66 \\
\hline Country of origin & & & & \\
\hline Born in the same country & & 1.00 & & \\
\hline Born in another country & 0.758 & 1.07 & 0.69 & 1.66 \\
\hline Number of drinks per day & & & & \\
\hline $1-3$ drinks & & 1.00 & & \\
\hline 4-6 drinks & $<0.001$ & 0.28 & 0.23 & 0.33 \\
\hline 7-9 drinks & $<0.001$ & 0.16 & 0.12 & 0.22 \\
\hline 10 or more drinks & $<0.001$ & 0.08 & 0.06 & 0.12 \\
\hline
\end{tabular}

${ }^{a}$ Odds ratio adjusted for all other variables in the table. 